\title{
The adaptive model of customs management
}

\author{
Viktor Makrusev ${ }^{1}$, Valentin Vakhrushev ${ }^{2,}{ }^{*}$ and Ekaterina Lyubkina ${ }^{1}$ \\ ${ }^{1}$ Russian Customs Academy, Komsomolsky pr. 4, 140015, Russia \\ ${ }^{2}$ Peoples' Friendship University of Russia, Miklukho-Maklaya str., 117198, Russia
}

\begin{abstract}
Nowadays the main features of the government administration are the formation of innovative theoretical and methodological bases of customs management basing on an integrative model. The authors described the conditions and directions of evolution of the institutional environment of the government administration. In the article is proposes concept of adaptive case management as one of the main area of development of customs management. This article presents adaptive model and the mechanism of its implementation.
\end{abstract}

\section{Introduction}

Nowadays the main features of the world economy development are the processes of world trade globalization and international monetary relations. Because of these changes scientific, technical and information exchanges are increasing and the migration of capital and labor has continued to grow. The applications of the unified technological standards are becoming widespread, common criteria of macroeconomic policy are being implemented faster, and so are such processes as unification of requirements for tax and employment policy, as well as for infrastructure and personnel. All the points mentioned above make new ways and open new opportunities in the global economy.

Globalization is developing successfully by regional integration of several countries leading to the unification of their economies into a single regional economic complex of a particular type. One of the actual ways of regional economic integration is the establishment of the Eurasian Economic Union (EAEU). It has international legal personality and is established by the Treaty on the Eurasian Economic Union. The EAEU provides for free movement of goods, services, capital and labor, pursues coordinated, harmonized and single policy in the sectors determined by the Treaty and international agreements within the Union.

Customs institute is a core element and an active regulator for the sphere of foreign economic activity (FEA) of the EAEU Member-States. It affects the political, economic, legal, energy, information and other communications directly or indirectly in the sphere of foreign economic relationship within the EAEU Member-States and with other world community. Thereby it aims to influence the sustainability and predictability of global and regional processes of foreign trade.

In a broad sense, customs institute is a system formation regulating activity of participants of foreign economic activity and providing the achievement of the main public

${ }^{*}$ Corresponding author: olgakalinina@bk.ru 
goal which is the protection of economic security of the EAEU Member-States by customs methods.

In the narrow sense of the term, "customs institution" is a complex of ideas, rules and mechanisms defining, shaping or developing a customs organization or the organization (the customs administration) as an open evolving system.

For example, Russian Federal customs service is a special institution, a state agency functioning and developing while transformation of the global economic parameters is happen.

In other words modern customs service is a big and complicated institution of ensuring economic security of the state which also has a status of a leading public institution. It performs a range of significant functions related to customs regulation of foreign trade activities.

Due to constantly raising requirements for the customs institution made by Customs serves participants and a global business community interested in the development of foreign trade, it is insufficient only to manage the current processes of customs administering.

The problems of managing development of such a complex system are the most important. The objective necessity in the development of innovative approaches to the management of customs institutions appears. There is a need for a mechanism which will provide a stable and effective activity of all customs services worldwide in the long term during globalization processes, macro-economic threats and increasing security requirements of countries.

The problems of customs institutions development create new requirements for a modern theory and methodology base of management which contains innovative international approaches and solutions. In fact it is a massive task of synthesis of the particular theory connecting and reflecting the progressive trends of evolution in public administration and management, integrative tendencies in international practice of foreign economic activity and customs service. The main aim of this article is the analysis of the problematic issues and key directions of the establishment and development of the management theory of customs service (customs management [4]).

Recently, there were big changes in the conditions of functioning of the public sector in Russia and in the whole world. Now the approaches and management methods for the private sector are often used by state agencies. This applies to the concept of customer orientation, strategic planning, delegation of powers, marketing, techniques of corporate culture management and many other phenomena.

All these changes are associated with the transition from the traditional model of public administration to the innovative (integrative) management model that combines the bureaucratic model and the model of marketing management. That is why the methods of state management are changing from command-administrative to market economy management methods. [6]

In the general case the classical administrative-bureaucratic control system is being gradually replaced by integrative model; the new elements of market economy management are also being implemented now. State sector (especially elementary levels) is gradually becoming a sphere of specific services. Particularly in the customs sphere not only the government provides the services (e.g. informing and counselling) but also private companies take part in this business (broker services, warehouse services, etc.). And some part of the customs services continue to transfer from public sector to private sector services. [5]

At the same time, public organizations are characterized by features that distinguish them from the commercial organizations. These features include the size and quality of goals, accountability, reporting and evaluation activities. That is why not all methods and 
techniques of management that are working in the private sector can be used effectively in the public agencies without any changes.

\section{Changes in the institutional sphere of customs management}

For the customs authorities the transition to an integrative model poses new challenges for the theoretical understanding of the ideas, principles, methods and technologies of customs management (theory of customs management). [2] At the same time customs system as an object of management consists of customs institutions, customs organizations (customs offices, functional and structural departments), customs functions and processes, customs resources and (or) customs services. The main challenge of customs management as a theory is a creation of single system of knowledge about the objects of customs management to achieve the goals of customs organizations in terms of operational, tactical and strategic changes in the objects and in the sphere of foreign trade.

To achieve the goal developing theory and methodology base of customs system is structured into the following areas:

- A fundamentally new paradigm of customs administration is formed. It is called the service paradigm or the paradigm of service-oriented administration. It is an innovative model of customs system as a whole which sets new conditions and provides necessary decisions for the maintenance and improvement of quality of customs services, as well as for the implementation of a quality management system in the practical management of customs services.

- Institutional changes are made in customs. Innovative ways or developing ideas of customs administrations, customs logistics and customs services are combined and implemented by a single process-oriented conceptual platform of international standards ISO 9000.

- Customs management as a theory develops comprehensively and purposefully and it combines the bureaucratic and market tools of management to solve the problems of safety and business support in foreign trade.

- A single methodological base of management is being created nowadays (cognitive approach). It consists of fundamental tools which organize, accumulate and use the knowledge about the evolution of customs systems (institutional, organizational, procedural, resource and service) in order to prepare and choose the rational management decisions.

- The tools and technological area of management are modernized. Customs technologies of marketing, monitoring, information controlling and "the Single Window" for customs administration are being created and implemented.

In such conditions the institutional sphere of customs management is evolving now. And its basic structural elements are the following: paradigm of administration, ideas of customs administration, customs management (management science), methodological basis of management and technological area of management.

In our opinion, the next step for the development of customs management is associated with the modernization of the theoretical concept of customs management. This concept has to reflect both the specifics of the developing institutional sphere and the conceptual basis of modern management.

There is an appropriate solution in this article. We formulated the concept of adaptive case management and propose a mechanism for its implementation combining the conceptual approaches to general management and the ideas for development of customs management using one platform. 


\section{Modern conceptual basis of management}

Despite the diversity of approaches, modern concepts of management can be grouped into several classes:

1. The concepts of an effective manager. They reflect the trend of an increasing role of a leading personality and raising his/her effectiveness by applying of the active approach, self-development, time-management.

2. The concepts of organizational development. They are oriented to the improvement of the organizational structure, optimizing all functions, raising the quality of staff and other ways and tools which the organization needs to achieve a sustainable functioning for the present and future periods.

3. The concepts of process management. They propose a broad implementation of the process approach into management, as well as the development of the operating area and creation of appropriate tools and technologies for the management.

4. The concepts of modernizing organizational culture. They propose the creation of a system of values based on competing models, monitoring and evaluation of their influence upon the individuals' attitude and behavior, as well as on organizational effectiveness.

5. The concepts of improving corporate culture. They focus on solving problems arising in functioning of the organization with the establishment of a self-development mechanism of its corporate culture. Changes start from the low level of a hierarchy.

\section{The idea of adaptive case management of customs system}

Innovations for the development of the theory of customs management are integrative. The ideas presented above are combined on the basis of the adaptive case approach. In fact, we formulate an integrative concept (the concept of adaptive case management). The main ideas are the following. Adaptive case management consists in:

1. Choosing a concept-oriented basis (A concept-oriented decision is a choice of conceptual basis from a lot of other concepts presented (effective management, organizational development, process management, organizational culture, corporate culture, etc.) depending on the conditions of the operational, tactical or strategic changes in the customs institution or its sphere (definition of the institutional space for adapting the management trajectories).

2. Preparation of and making relevant decisions because of the changes both in the management system and in the structure of its institutional sphere (Changes in the structure of the institutional sphere are changes in the paradigm of customs administration, customs management, methodological base of management, technological sphere of management).

The institutional space for adaptation of management trajectories is described by the corresponding matrix presented in table 1. The matrix denotes a lot of achievable trajectories of management in the form of acceptable (effective) changes in the institutional sphere. But the conditions of operational, tactical or strategic changes and a lot of conceptoriented and management decisions set space ("a tube") of the case trajectories of management.

Shaping the space of these trajectories, we form and develop the adaptive opportunities of a management system. Management in these conditions means a selection of the necessary (adaptive case) trajectory of management to achieve the desired or projected outcome from the great amount of acceptable (effective) solutions. [9] 
Table 1. The space of adaptation management trajectories as a set of acceptable (effective) solutions.

\begin{tabular}{|c|c|c|c|c|c|c|}
\hline $\begin{array}{l}\text { The structural elements of the institutional } \\
\text { sphere/Concept-oriented solutions }\end{array}$ & 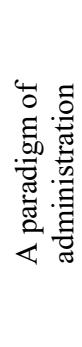 & 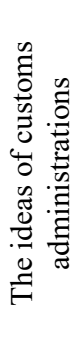 & 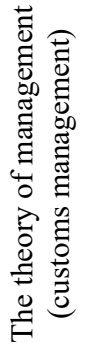 & 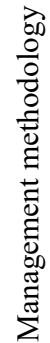 & 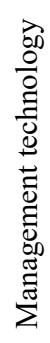 & \\
\hline Effective management & & & & & & \multirow{5}{*}{ 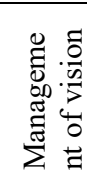 } \\
\hline Organizational development & + & + & & & & \\
\hline Process management & & + & + & + & & \\
\hline Organizational culture & & & + & & & \\
\hline Corporate culture & & & & & + & \\
\hline
\end{tabular}

\section{The graphic and analytical model of adaptive case management}

In fact, in these circumstances adaptive case management is a management by "flexible" trajectory. The corresponding graphic model of adaptive case management is shown by Fig. 1. The initial position and the goal (the expected result) are defined by this model. The achievement of the goal happens during the process of functioning by performing the intermediate results. When we receive an intermediate result of functioning and if the result is not the same as the desired intermediate result in the space of the trajectories we have to choose a new (adapted) trajectory of functioning.

The main feature of this approach is that management is carried out not only by deviations, but also by identifying a new target trajectory in the space of progressive goals and in the context of vision. That is why it is necessary to forecast changes of the monitored parameters with adjustment proposals.

In this approach the methods and techniques of management evolve from the intuitive methods to the information-analytical technologies and technologies for the preparation and adoption of collective management decisions based on information.

All this information can be generated and accumulated by business projects, trainings, expert and analytical modelling in the sphere of case-analyzing centers on the basis of cognitive and productive upgrade-technology of management [4].

A diagram illustrating such a mechanism of management is depicted in Fig. 2.

Holistic and evolutionary management approach, which presents the development of the management paradigm of organizations, is the basis of the mechanism [4]. The mechanism of adaptive case management consists of four feedback loops to provide the adjustment of a management system in accordance with a program and the adjustment of a program or a plan on the basis of the goal and its change in the context of the vision. 


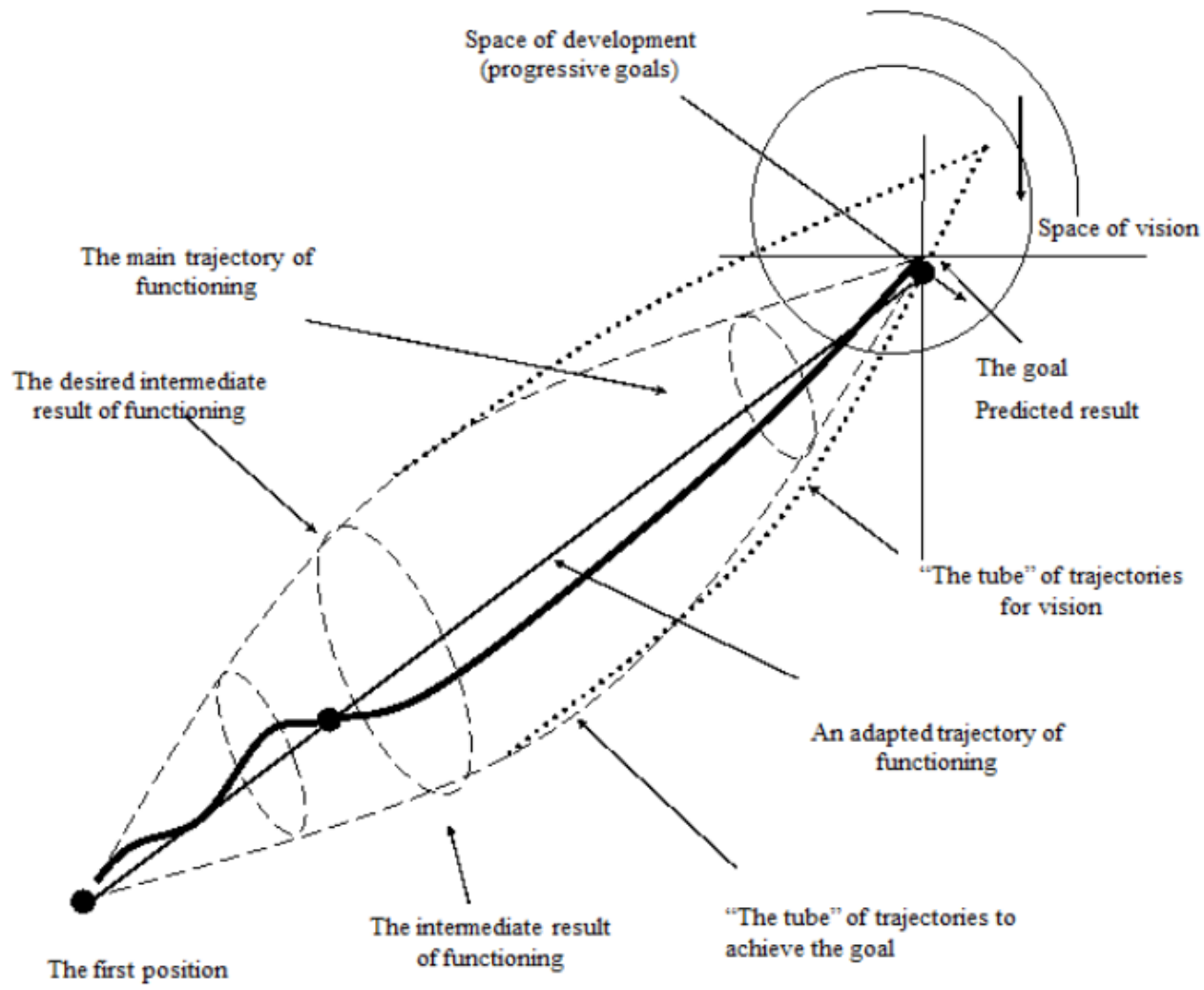

Fig. 1. The graphic and analytical model of adaptive case management.

\section{The adaptive case management mechanism of customs service}

The mechanism suggests the possibility of changing (evolution), not only for a plan, but also for a goal and vision of a customs organization. Although the goal is an internal inducement of management, a determining factor of the goal-setting is the vision of the organization represented by a certain system of values, which is formed, for example, as a part of the corporate culture of the organization. It consists of the most sustainable category of human relations which was formed and developed throughout the previous experience of practical and intellectual activities. The system of values acts as the basis for goal setting and as a global criterion of management at the same time.

The adaptive case management mechanism of customs organizations can be viewed as a model of the generalized management concept. The mechanism is integrative and will act as the main thing in the theory and practice of customs management in the near future.

In this mechanism the relevant value system (vision) closes the input and output of the management system being both a global criterion and the basis for goal-setting. At the same time the system of values changes the management system from the target category to the natural category oriented to natural development implying a continuity of the cybernetic and synergetic approaches in management theory. 


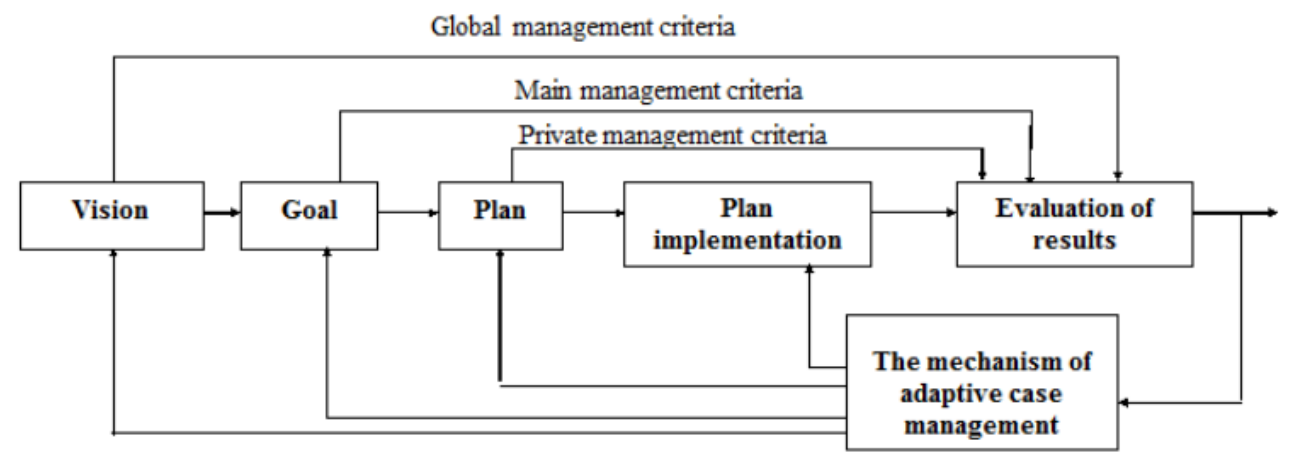

Fig. 2. The adaptive case management mechanism of customs institutions.

Thus, further improvement of customs service and management of customs institutions is based on the complex of solutions defining the concept of service customs and ensuring its effective implementation (using the mechanism of adaptive case management, marketing tools and monitoring of customs services). In this case the concept of service-oriented customs administration, the mechanisms of adaptation management and marketing (monitoring) tools are the main elements in a system project of strategic development of the Russian customs authorities.

Customs management as a theoretical platform of customs management is specific and represents a particular developing area for research. Nowadays, the most relevant problem areas for the development of customs management are the following ones:

1. The problem of creation and realization of the concept of service-oriented administration as a management object [6].

2. The problem of developing an integrative model of the customs management based on traditional models and models of service-oriented administration as a tool for analysis, modelling and forecasting [2].

3. The problem of modernizing the complex of tasks for supporting and decision-making processes using controlling technology, the development of methodical and softwaretechnical base for its automation [7].

4. The problem of integrating the technological platforms of customs administration and management using the principles of "the Single Window", the development of a network of case-analyzing centers for the implementation of analytical management activity of customs administrations in the EAEU Member-States using the principles of adaptive case management $[4,5]$.

5. The problem of creating a harmonized and balanced system of indicators for appreciation of the efficiency of customs authorities adapted to the conditions of economic integration.

To draw the conclusion, problems of customs management theory are comprehensive and cover all levels for special theories. They are problems of a conceptual nature, the problems of searching for adequate models and methods to create and modernize technologies and management systems of customs authorities.

\section{References}

1. V.V. Makrusev, Bulletin of the Russian University of Economics named after G. V. Plekhanov, 2(92) (2017)

2. V.V. Makrusev, M.A. Mesyats, Humanitarian and social Sciences, 4 (2011) 
3. M.V. Boikova, Bulletin of Moscow state regional University. Series: Economics, 1 (2015)

4. V.V. Makrusev, Customs management: the textbook (Berlin: Direkt-Media, Moscow, 2015)

5. V.V. Makrusev, Bulletin of the Russian customs Academy, 2(31) (2015)

6. V.V. Makrusev, Scientific discussion: questions of Economics and management, 11(55) (2016)

7. V.V. Makrusev, Marketing of customs services (Prospect, Moscow, 2017)

8. S.Y. Yusupova, V.V. Makrusev, M.V. Boikova, Management of economic systems: electronic scientific journal, 2(96) (2017)

9. D.G. Zerkin, Eurasian scientific Association 2(3), 15 (2016)

10. K.B. Safonov, Modern science: Actual problems of theory and practice, Series "Humanitarian Sciences", 4 (2011) 